\title{
Ultrasensitive determination of cadmium in seawater by hollow fiber supported liquid membrane extraction coupled with graphite furnace atomic absorption spectrometry
}

\author{
Jin-feng Peng, Rui Liu, Jing-fu Liu *, Bin He, Xia-lin Hu, Gui-bin Jiang \\ State Key Laboratory of Environmental Chemistry and Ecotoxicology, Research Center for Eco-Environmental Sciences, \\ Chinese Academy of Sciences, P. O. Box 2871, Beijing 100085, China \\ Received 19 December 2006; accepted 11 April 2007 \\ Available online 22 April 2007
}

\begin{abstract}
A new procedure, based on hollow fiber supported liquid membrane preconcentration coupled with graphite furnace atomic absorption spectrometry (GFAAS) detection, was developed for the determination of trace $\mathrm{Cd}$ in seawater samples. With 1-octanol that contained a mixture of dithizone (carrier) and oleic acid immobilized in the pores of the polypropylene hollow fiber as a liquid membrane, Cd was selectively extracted from water samples into $0.05 \mathrm{M} \mathrm{HNO}_{3}$ that filled the lumen of the hollow fiber as a stripping solution. The main extraction related parameters were optimized, and the effects of salinity and some coexisting interferants were also evaluated. Under the optimum extraction conditions, an enrichment factor of 387 was obtained for a $100-\mathrm{mL}$ sample solution. In combination with graphite furnace atomic absorption spectrometry, a very low detection limit $\left(0.8 \mathrm{ng} \mathrm{L}^{-1}\right)$ and a relative standard deviation $\left(2.5 \%\right.$ at $50 \mathrm{ng} \mathrm{L}^{-1}$ level) were achieved. Five seawater samples were analyzed by the proposed method without dilution, with detected Cd concentration in the range of 56.4-264.8 $\mathrm{ng} \mathrm{L}^{-1}$ and the relative spiked recoveries over $89 \%$. For comparison, these samples were also analyzed by the Inductively Coupled Plasma Mass Spectrometry (ICP-MS) method after a 10fold dilution for matrix effect elimination. Statistical analysis with a one-way ANOVA shows no significant differences (at 0.05 level) between the results obtained by the proposed and ICP-MS methods. Additionally, analysis of certified reference materials (GBW (E) 080040) shows good agreement with the certified value. These results indicate that this present method is very sensitive and reliable, and can effectively eliminate complex matrix interferences in seawater samples.
\end{abstract}

(C) 2007 Elsevier B.V. All rights reserved.

Keywords: Cadmium; Seawater; Hollow fiber; Supported liquid membrane extraction; Graphite furnace atomic absorption spectrometry

\section{Introduction}

The determination of trace or ultratrace $\mathrm{Cd}$ in seawater is of great interest since it is a way to assess the early impact of human activities on the marine environment [1]. High concentration of salt (approximately 3\%) and very low content of cadmium in seawater are the two major problems that preclude the development of a simple approach for this determination. Nowadays, a few sensitive analytical tools such as Inductively Coupled Plasma Mass Spectrometry (ICP-MS) are available for the determination of trace heavy metals. However, the very high cost of the ICP-MS instrument and its operating expenses are a

\footnotetext{
* Corresponding author. Tel.: +861062849192.
}

E-mail address: jfliu@rcees.ac.cn (J. Liu). heavy burden for a common laboratory. Furthermore, it is very difficult to achieve satisfactory results for seawater analysis due to the serious interferences related to its high salinity. Because of its high sensitivity, low cost and easy operation, graphite furnace atomic absorption spectrometry (GFAAS) has been frequently used for the determination of trace $\mathrm{Cd}$ in seawater [1-3]. To eliminate the matrix effects, several separation and preconcentration procedures have been proposed, based on solution-phase chelation followed by adsorption onto reversed-phase $\mathrm{C}_{18}$ substrates [4-6], or retention on chelating resins or activated carbon [7-9], coprecipitation [10], cloud point extraction [11,12] and flow injection on-line preconcentration techniques [13,14].

As an alternative, supported liquid membrane (SLM) extraction was successfully applied to enrich trace metals [15]. In the SLM extraction of metals, a key issue is how to select the 
appropriate solvent for extraction as well as the carrier for transporting the metal ions from the sample solution to the stripping solution. Dihexyl ether, isooctane, $n$-undecane, toluene, kerosene, and 1-octanol were used as the membrane liquid. Macrocyclic crown ethers like 1,10-didecyl-1,10-diaza18-crown-6, organophosphorus extractants like di-2-ethylhexyl phosphoric acid (DEHPA) and tri- $n$-butyl phosphate (TBP), thiourea and dithizone were commonly used as the carrier to form complexes with the metal ions.

There are many SLM extraction devices, but the hollow fiber supported liquid membrane (HFSLM) extraction system is one of the most efficient devices that have been developed. HFSLM is usually composed of three distinct compartments: an internal stripping solution (filled in the hollow fiber lumen), a hydrophobic liquid membrane (immobilized in the hollow fiber pores), and an external sample solution (containing the analytes). HFSLM has some specific advantages: the hollow fiber itself can effectively exclude high molecular weight species and particles present in the sample solution; the extraction system can be easily set up; and the hollow fiber is disposable and therefore eliminates the carry-over between determinations.

In this study, 1-octanol that dissolved the mixture of oleic acid and dithizone was immobilized in the pores of the polypropylene hollow fiber to form a liquid membrane for the extraction of $\mathrm{Cd}$. Dithizone was used as a carrier, while oleic acid was adopted to prevent the loss of the liquid membrane. This proposed HFSLM procedure can eliminate the interferences from seawater samples, as well as the complex matrix effects in graphite furnace atomic absorption spectrometry analysis.

\section{Experimental}

\subsection{Apparatus}

GFAAS measurements were carried out using a Hitachi Z-5700 graphite furnace atomic absorption spectrometer with Zeemaneffect background correction (Hitachi High-Technologies Corporation, Japan). A cadmium hollow cathode lamp (Beijing ShuGuangMing Electronic Lighting Instrument Co., Ltd., Beijing, China) was used as radiation source at $228.8 \mathrm{~nm}$. The optimum operating parameters for the spectrometer are shown in Table 1. A $10-\mu \mathrm{L}$ aliquot of sample was manually injected into the furnace, and absorbance signals in the form of peak height were measured.

\subsection{Reagents and materials}

The stock standard solution of Cd (II) $\left(1000 \mu \mathrm{g} \mathrm{mL}^{-1}\right)$ was purchased from the National Research Center for Reference Material (Beijing, China). Working standard solutions were obtained by appropriate dilution of the stock standard solution with $2 \%$ nitric acid $(\mathrm{v} / \mathrm{v})$. Dithizone $(\geq 98 \%)$ and 1-octanol ( $\geq 99 \%$ ) were obtained from A Johnson Matthey Company (Alfa Aesar, USA). Oleic acid ( $\geq 97 \%)$ and 1,10-dicyclohexano-18-crown-6 ( $\geq 98 \%$ ) were purchased from Acros Organics (Acros, Belgium). The nitric acid used in the experiments (suprapure grade) was obtained from Beijing Chemicals Corporation (Beijing, China). Other standard solutions of
Table 1

Instrumental operating conditions (GFAAS)

\begin{tabular}{lllllll}
\hline Analyte & $\begin{array}{l}\text { Wavelength } \\
(\mathrm{nm})\end{array}$ & $\begin{array}{l}\text { Injection } \\
\text { mode }\end{array}$ & $\begin{array}{l}\text { Sample } \\
\text { volume } \\
(\mu \mathrm{L})\end{array}$ & Modifier & $\begin{array}{l}\text { Spectral } \\
\text { band width } \\
(\mathrm{nm})\end{array}$ & $\begin{array}{l}\text { Lamp } \\
\text { current } \\
(\mathrm{mA})\end{array}$ \\
\hline $\mathrm{Cd}$ & 228.8 & Manual & 10 & - & 0.4 & 5.0
\end{tabular}

Temperature program

\begin{tabular}{|c|c|c|c|c|}
\hline \multirow[t]{2}{*}{ Stage } & \multicolumn{2}{|c|}{ Temperature $\left({ }^{\circ} \mathrm{C}\right)$} & \multicolumn{2}{|c|}{ Time (s) } \\
\hline & Start & End & Ramp & Hold \\
\hline Drying & 80 & 140 & 40 & 0 \\
\hline Pyrolysis & 350 & 350 & 20 & 0 \\
\hline Atomization & 1700 & 1700 & 0 & 5 \\
\hline Cleaning & 1800 & 1800 & 0 & 4 \\
\hline
\end{tabular}

metal ions like $\mathrm{Pb}$ (II), Mo (II), Sn (II), Ca (II), Fe (III), Mg (II), Zn (II), Ba (II) used in the interference experiments were purchased from the National Research Center for Reference Material. Sodium chloride ( $\mathrm{NaCl})$ (spectroscopically pure) was purchased from Beijing Chemicals Corporation. The anions (sulfate and chloride) were prepared by dissolving spectroscopically pure potassium sulfate $\left(\mathrm{K}_{2} \mathrm{SO}_{4}\right)$ and potassium chloride (KCl) (Beijing Chemicals Corporation, Beijing) in ultrapure water (Easypure LF). The certified reference materials, GBW (E) 080040 (seawater), were from the Second Oceanography Institute of China (Hangzhou, China).

The $\mathrm{pH}$ of the sample solutions was adjusted with $0.04 \mathrm{~mol}$ $\mathrm{L}^{-1}$ lithium hydroxide or $1 \%(\mathrm{v} / \mathrm{v})$ nitric acid. A pH $211 \mathrm{pH}$ meter (Hanna Instruments, Italy) was used for the $\mathrm{pH}$ determination. All the other chemicals were at least of analytical grade and ultrapure water produced by an Easypure LF (Barnstead International, Dubuque, IA, USA) equipment was used throughout. The vessels used for trace analysis were kept in $30 \%(\mathrm{v} / \mathrm{v})$ nitric acid for at least $48 \mathrm{~h}$ and subsequently washed four times with ultrapure water. To avoid blank contributions from the reagents, tests by AAS were performed prior to use.

The Q 3/2 Accurel polypropylene hollow fiber membrane (600 $\mu \mathrm{m}$ i.d., $200 \mu \mathrm{m}$ wall thickness, $0.2 \mu \mathrm{m}$ pore size) was purchased from Membrana, Wuppertal, Germany. A $25-\mu \mathrm{L}$ microsyringe (Agilent, USA) with a needle of $0.5-\mathrm{mm}$ outer diameter was used to flush the inner wall of the hollow fiber and introduce the stripping solutions into the lumen of the hollow fiber for extraction. Seawater samples were collected from Yantai, the Bohai Sea of China. The samples were all stored at the temperature of $4{ }^{\circ} \mathrm{C}$.

\subsection{Extraction procedure}

Extraction was performed as follows: the porous hollow fiber that was cut carefully into $4.5-\mathrm{cm}$ length pieces was immersed in 1-octanol solution containing dithizone or mixture of dithizone and oleic acid, for a prescribed time. The hollow fiber was taken out and washed outside and inside five times with water. The needle of the microsyringe holding $\sim 20 \mu \mathrm{L}$ of the stripping solution was connected to the fiber and the plunger of the microsyringe was depressed to flush out its content to wash and fill the lumen of the hollow fiber. Care was taken to 
avoid any air bubbles. After that, the two ends of the fiber were sealed with heated tweezers. By this preparation, the obtained HFSLM device had an effective fiber length of $\sim 4.0 \mathrm{~cm}$ with acceptor phase volume of $\sim 10 \mu \mathrm{L}$. The extraction was carried out by placing the hollow fiber in $100 \mathrm{~mL}$ of aqueous solution in a $150-\mathrm{mL}$ beaker. After stirring for a prescribed time, the hollow fiber was taken out from the solution and one of the sealed ends was cut to allow its connection with the microsyringe needle; the other sealed end was then cut to permit the flushing of the stripping solution to a $200-\mu \mathrm{L}$ glass vial. This solution in the glass vial was directly injected into the AAS or after an appropriate dilution. The used fiber was discarded and a fresh one was used for the next extraction.

\subsection{Enrichment factor}

For investigating the relevant parameters affecting the extraction, the enrichment factor $\left(E_{\mathrm{e}}\right)$ defined as: $E_{\mathrm{e}}=C_{\mathrm{A}} / C_{\mathrm{S}}$ was selected as response, in which $C_{\mathrm{A}}$ and $C_{\mathrm{S}}$ are the concentrations of analytes in the acceptor (stripping solution) and extracted sample solutions, respectively.

\section{Results and discussion}

\subsection{Selection of the carrier and its concentration}

Macrocyclic crown ethers have been extensively applied as chelating agent in the determination of many metallic elements in the past decades. But preliminary experiments showed that 1,10-dicyclohexano-18-crown-6 did not extract $\mathrm{Cd}^{2+}$ from the sample solution efficiently. Therefore, dithizone that can selectively complex many transition metal ions [16] was adopted as the carrier in the present study.

In general, the transport of metal ions through SLM is based on one of the three possible mechanisms: proton-drive, aniondrive, and metal ion counter gradient-drive [17]. According Ref. [18], the most probable transport mechanism for $\mathrm{Cd}^{2+}$ through HFSLM is proton-drive. In the sample/membrane interface, the proton of dithizone was exchanged by $\mathrm{Cd}^{2+}$ to form a $\mathrm{Cd}-$ dithizone complex in the liquid membrane and released $\mathrm{H}^{+}$into the sample, then the $\mathrm{Cd}$-dithizone complex diffused to the membrane/stripping solution interface where dithizone was protonated and $\mathrm{Cd}^{2+}$ was released into the stripping solution.

Concerning the effect of the carrier concentration, $E_{\mathrm{e}}$ increased with the concentration of dithizone up to $0.8 \mathrm{mg}$ $\mathrm{L}^{-1}$, and remained constant up to $1.2 \mathrm{mg} \mathrm{L}^{-1}$. A further increase was observed at $1.6 \mathrm{mg} \mathrm{L}^{-1}$, followed by a decrease back to the previous value at $2.0 \mathrm{mg} \mathrm{L}^{-1}$. Thus, $1.6 \mathrm{mg} \mathrm{L}^{-1}$ dithizone in 1octanol was selected for the following experiments.

\subsection{Optimization of extraction conditions}

\subsubsection{Effect of sample solution acidity}

The $\mathrm{pH}$ influence was studied by adding $0.05 \mathrm{~mol} \mathrm{~L}^{-1}$ nitric acid or $0.04 \mathrm{~mol} \mathrm{~L}^{-1}$ lithium hydroxide into the sample solution, and maximum $E_{\mathrm{e}}$ values were observed between $\mathrm{pH} 5.2$ and 6.4. When sample solution $\mathrm{pH}$ was $8.2,9 \%$ of $E_{\mathrm{e}}$ decrease was observed. With the further increase of $\mathrm{pH}, E_{\mathrm{e}}$ decreased from $322(\mathrm{pH} \mathrm{8.2)}$ to $233(\mathrm{pH} 8.9)$. The possible reason is that dithizone is much more easily dissolved in basic solution [19]. Taking this into account, $\mathrm{pH} 5.2$ was selected as the optimum sample solution acidity for the following investigations.

\subsubsection{Effect of the stripping solution concentration}

For stripping of the metal ions from supported liquid membrane phase, strong acidic solutions are used. Therefore, nitric acid solutions with concentrations ranging from $0.01 \mathrm{~mol}$ $\mathrm{L}^{-1}$ to $1.0 \mathrm{~mol} \mathrm{~L}-1$ were investigated as stripping solution. $E_{\mathrm{e}}$ increased with $\mathrm{HNO}_{3}$ concentration up to $0.05 \mathrm{~mol} \mathrm{~L}^{-1}$ and decreased with the further increase of the $\mathrm{HNO}_{3}$ concentration. Thus, $0.05 \mathrm{~mol} \mathrm{~L}^{-1}$ nitric acid was used as the stripping solution. Further studies showed that $E_{\mathrm{e}}$ decreased with the addition of lithium nitrate $\left(0.05\right.$ to $\left.1.0 \mathrm{~mol} \mathrm{~L}^{-1}\right)$ to the stripping solution $\left(0.05 \mathrm{~mol} \mathrm{~L}^{-1} \mathrm{HNO}_{3}\right)$. This probably is due to the decreased $\mathrm{H}^{+}$ activity and thus the proton driving force was weakened with the addition of lithium nitrate.

\subsubsection{Effect of stirring rate}

Usually, a higher stirring rate can accelerate the diffusion of the analytes and reduce the time necessary to reach the dynamic equilibrium in HFSLM. In this experiment, the stirring rate was divided into three different classes: low, medium and high. The results showed that the medium stirring rate was appropriate to obtain the highest extraction efficiency. A too high stirring rate caused many bubbles to attach on the surface of the hollow fiber, and impeded the transfer of the analyte. Therefore, a medium stirring rate was chosen in the following studies.

\subsubsection{Effect of extraction period}

Experimental results indicate that, with no oleic acid addition, $E_{\mathrm{e}}$ reached its maximum at an extraction time of $30 \mathrm{~min}$ and then decreased rapidly. This may be attributed to the loss of the dithizone in HFSLM when it was exposed to the aqueous solution for a long time. Based on the optimum result of Ref. [20], $2.08 \mathrm{~g} \mathrm{~L}^{-1}$ of oleic acid was added into the membrane phase to prevent the loss of dithizone from the membrane phase to the aqueous phase. The results demonstrate that the maximum $E_{\mathrm{e}}$ is reached with the extraction period in the range of 25-35 min. Consequently, $30 \mathrm{~min}$ was selected as the optimum extraction period and $2.08 \mathrm{~g} \mathrm{~L}^{-1}$ oleic acid was added into the membrane liquid.

\subsection{Interference evaluation}

When HFSLM is used for the treatment of real samples, potentially interfering ions might be present. According to the composition of common seawater [21], a series of metal ions (Table 2) (the corresponding anions are nitrate or chloride) were selected for evaluation of the robustness of the proposed method in relation to this kind of interference. Fluoride, chloride, bromide, iodide, sulfate and phosphate (the corresponding cation is potassium) were also investigated as interfering species. The ratios of interferant to analyte are at least equal to or larger than those in common seawater. The results shown 
in Table 2 indicate that the recoveries are $91-108 \%$ in the presence of all studied ions.

In addition, it is well known that the high concentration of salt in seawater may seriously affect the AAS determination of Cd. Therefore, varied amounts of sodium chloride that covered the normal concentration of salt in seawater were added into the aqueous solutions to evaluate the interference of salt. When the sample solutions spiked with $0.5 \mu \mathrm{g} \mathrm{L}^{-1} \mathrm{Cd}$ were added with $3 \%$ and $4 \%(\mathrm{w} / \mathrm{v})$ sodium chloride, relative spiked recoveries of $91.7 \%$ and $90.4 \%$ respectively could be achieved. Therefore, the influence of salinity in seawater is not significant for the extraction.

\subsection{Analytical performance and validation}

Some characteristics of the proposed method such as enrichment factor, linear range, correlation coefficients, limit of detection (LOD) and repeatability were all investigated by extracting $100 \mathrm{~mL}$ of $\mathrm{Cd}$ standard solutions. The results indicated that an enrichment factor of 387 can be obtained under the optimum extraction conditions. Analytical curves performed after HFSLM preconcentration exhibited good linearity with correlation coefficient $r^{2}>0.999$, in the range of $0.01-1 \mu \mathrm{g} \mathrm{L}-1$ $\mathrm{Cd}$. The limit of detection, calculated from the standard deviation of 5 blank measurements of the whole analytical procedure, was $0.8 \mathrm{ng} \mathrm{L}^{-1}$, which is far lower than the instrumental detection limit $\left(0.2 \mu \mathrm{g} \mathrm{L}^{-1}\right)$ and is comparable to that obtained with ICP-MS [22]. The relative standard deviation calculated from five replicate experiments at $200 \mathrm{ng} \mathrm{L}^{-1}$ was lower than $3.0 \%$.

For validation, five seawater samples were analyzed by both the proposed method and the ICP-MS method. Sample analysis by the proposed method was conducted without dilution, whereas the analysis by the ICP-MS method was performed after a 10 -fold dilution for eliminating the matrix interferences.

Table 2

Influence of interferants on the extraction and determination of $\mathrm{Cd}\left(0.5 \mu \mathrm{g} \mathrm{L}^{-1}\right)$

\begin{tabular}{llr}
\hline Interferant & $\begin{array}{l}\text { Interferant to analyte } \\
\text { ratio }(\mathrm{w} / \mathrm{w})\end{array}$ & $\begin{array}{r}\text { Recovery }(\%, \\
\text { mean } \pm \text { S.D., } n=3)\end{array}$ \\
\hline $\mathrm{K}^{+}$(IA) & $4 \times 10^{7}$ & $91 \pm 1$ \\
$\mathrm{Na}^{+}$(IA) & $2.7 \times 10^{8}$ & $92 \pm 3$ \\
$\mathrm{Li}^{+}$(IA) & 2000 & $100 \pm 1$ \\
$\mathrm{Ca}^{2+}$ (IIA) & $4 \times 10^{6}$ & $99 \pm 6$ \\
$\mathrm{Mg}^{2+}$ (IIA) & $1.2 \times 10^{7}$ & $98 \pm 1$ \\
$\mathrm{Ba}^{2+}$ (IIA) & 200 & $103 \pm 2$ \\
$\mathrm{~Pb}^{2+}$ (IVA) & 50 & $94 \pm 1$ \\
$\mathrm{Sn}^{2+}$ (IVA) & 1000 & $100 \pm 9$ \\
$\mathrm{Cu}^{2+}$ (IB) & 10 & $98 \pm 3$ \\
$\mathrm{Hg}^{2+}$ (IIB) & 10 & $97 \pm 4$ \\
$\mathrm{Mo}^{2+}$ (VIB) & 500 & $104 \pm 1$ \\
$\mathrm{Mn}^{2+}$ (VIIB) & 1000 & $100 \pm 2$ \\
$\mathrm{Co}^{2+}$ (VIII) & 10 & $108 \pm 3$ \\
$\mathrm{Fe}^{3+}$ (VIII) & 30 & $91 \pm 2$ \\
$\mathrm{~F}^{-}$ & $1.2 \times 10^{5}$ & $97 \pm 2$ \\
$\mathrm{Cl}^{-}$ & $3.8 \times 10^{7}$ & $91 \pm 1$ \\
$\mathrm{Br}^{-}$ & $6 \times 10^{5}$ & $94 \pm 1$ \\
$\mathrm{I}^{-}$ & 600 & $92 \pm 5$ \\
$\mathrm{SO}_{4}^{2-}$ & $2.4 \times 10^{7}$ & $94 \pm 1$ \\
$\mathrm{PO}_{4}^{3-}$ & $3 \times 10^{4}$ & $92 \pm 3$ \\
\hline
\end{tabular}

Table 3

Analytical results of real samples (mean \pm S.D., $n=3$ )

\begin{tabular}{lcrlc}
\hline Sample & $\begin{array}{l}\text { Found in natural } \\
\text { sample (ng L } \\
\text { (HFSLM-AAS) }\end{array}$ & Spiked $\left(\mathrm{ng} \mathrm{L}^{-1}\right)$ & Recovery (\%) & $\begin{array}{l}\text { Found in natural } \\
\text { sample (ng L } \\
\text { (ICP-MS) }\end{array}$ \\
\hline S1 & $264.8 \pm 2.8$ & 200 & $89.0 \pm 1.0$ & $246.0 \pm 1.6$ \\
S2 & $56.4 \pm 1.1$ & 50 & $89.3 \pm 2.0$ & $54.0 \pm 1.8$ \\
S3 & $127.3 \pm 1.0$ & 100 & $99.7 \pm 1.0$ & $122.0 \pm 1.6$ \\
S4 & $104.0 \pm 4.0$ & 100 & $96.9 \pm 1.0$ & $116.0 \pm 0.9$ \\
S5 & $125.6 \pm 3.2$ & 100 & $97.5 \pm 2.0$ & $123.0 \pm 1.9$ \\
\hline
\end{tabular}

The analytical results shown in Table 3 demonstrate that the results by using the present method are consistent with those obtained by ICP-MS. Statistical analysis with a one-way ANOVA showed no significant differences (at 0.05 level) between the results obtained by these two methods. In addition, the cadmium content of certified reference materials (GBW (E) 080040 seawater) determined by the proposed method $(0.95 \pm$ $0.07 \mu \mathrm{g} \mathrm{L}^{-1}$, mean \pm S.D., $n=3$ ) shows good agreement with the certified values $\left(1.00 \pm 0.06 \mu \mathrm{g} \mathrm{L}^{-1}\right)$ [23].

\section{Conclusion}

A novel preconcentration procedure for determination of trace $\mathrm{Cd}$ in seawater has been developed in this study. The hollow fiber supported liquid membrane extraction device showed an interference free performance. After optimization of the extraction conditions, an enrichment factor as high as 387 could be achieved. Coupled with graphite furnace atomic absorption spectrometry, Cd concentration down to a few nanograms per liter level in seawater samples could be determined.

\section{Acknowledgements}

This work was jointly supported by the Chinese Academy of Sciences (KJCX2-SW-H06, KZCX3-SW-431) and the National Basic Research Program of China (2002CB412308).

\section{References}

[1] F.M. Fernández, J.D. Stripeikis, M.B. Tudino, O.E. Troccoli, Fully automatic on-line separation preconcentration system for electrothermal atomic absorption spectrometry: determination of cadmium and lead in sea-water, Analyst 122 (1997) 679-684.

[2] R. Guevremont, Organic matrix modifiers for direct graphite furnace atomic absorption determination of cadmium in sea water, Anal. Chem. 52 (1980) 1574-1578.

[3] H.J. Chang, Y.H. Sung, S.D. Huang, Determination of ultra-trace amounts of cadmium, cobalt and nickel in sea-water by electrothermal atomic absorption spectrometry with on-line preconcentration, Analyst 124 (1999) 1695-1699.

[4] Z. Fang, M. Sperling, B. Welz, Flow injection on-line sorbent extraction pre-concentration for graphite furnace atomic absorption spectrometry, J. Anal. At. Spectrom. 5 (1990) 639-646.

[5] M. Sperling, X. Yin, B. Welz, Flow injection on-line separation and preconcentration for electrothermal atomic absorption spectrometry. Part 1 . Determination of ultratrace amounts of cadmium, copper, lead and nickel in water samples, J. Anal. At. Spectrom. 6 (1991) 295-300.

[6] V. Porta, O. Abollino, E. Mentasti, C. Sarzanini, Determination of ultratrace levels of metal ions in sea-water with on-line pre-concentration and 
electrothermal atomic absorption spectrometry, J. Anal. At. Spectrom. 6 (1991) 119-122.

[7] F.M. Fernández, M.B. Tudino, O.E. Troccoli, Automatic on-line ultratrace determination of $\mathrm{Cd}$ species of environmental significance in natural waters by FI-ETAAS, J. Anal. At. Spectrom. 15 (2000) 687-695.

[8] Y.H. Sung, Z.S. Liu, S.D. Huang, Automated on-line preconcentration system for electrothermal atomic absorption spectrometry for the determination of copper and molybdenum in sea-water, J. Anal. At. Spectrom. 12 (1997) 841-847.

[9] M.T.S. Cordero, E.I.V. Alonso, P.C Rudner, A.G. de Torres, J.M.C. Pavón, Computer-assisted SIMPLEX optimisation of an on-line preconcentration system for determination of nickel in sea-water by electrothermal atomic absorption spectrometry, J. Anal. At. Spectrom. 14 (1999) 1033-1037.

[10] K. Atsumi, T. Minami, J. Ueda, Determination of cadmium in spring water by graphite-furnace atomic absorption spectrometry after coprecipitation with ytterbium hydroxide, Anal. Sci. 21 (2005) 647-649.

[11] C.G.. Yuan, G..B. Jiang, Y.Q. Cai, B. He, J.F. Liu, Determination of cadmium at the nanogram per liter level in seawater by graphite furnace AAS using cloud point extraction, At. Spectr. 170 (2004) 170-176.

[12] X.S. Zhu, X.H. Zhu, B.S. Wang, Determination of trace cadmium in water samples by graphite furnace atomic absorption spectrometry after cloud point extraction, Microchim. Acta 154 (2006) 95-100.

[13] J. Nakajima, Y. Hirano, K. Oguma, Determination of lead in seawater by flow-injection on-line preconcentration-electrothermal atomic absorption spectrometry after coprecipitation with iron(III) hydroxide, Anal. Sci. 19 (2003) 585-588.

[14] Z. Fang, T. Guo, B. Welz, Determination of cadmium, lead and copper in water samples by flame atomic-absorption spectrometry with preconcen- tration by flow-injection on-line sorbent extraction, Talanta 38 (1991) 613-619.

[15] M. Papantoni, N.K. Djane, K. Ndung'u, J.Å. Jönsson, L. Mathiassonm, Trace enrichment of metals using a supported liquid membrane technique, Analyst 120 (1995) 1471-1477.

[16] A. Albert, W.S. Gledhill, The choice of a chelating agent for inactivating trace metals: I. A survey of commercially available chelating agents, Biochem. J. 41 (1947) 529-533.

[17] N. Parthasarathy, M. Pelletier, J. Buffle, Hollow fiber based supported liquid membrane: a novel analytical system for trace metal analysis, Anal. Chim. Acta 350 (1997) 183-195.

[18] The National Standards of the People's Republic of China: GB 7471-87, Water quality determination of cadmium - spectrophotometric method with dithizone, State Environmental Protection Administration of China, 1987.

[19] E.B. Sandell, The primary dissociation constant of diphenylthiocarbazone, J. Am. Chem. Soc. 72 (1950) 4660-4661.

[20] R. Romero, J.Å. Jönsson, Determination of free copper concentrations in natural waters by using supported liquid membrane extraction under equilibrium conditions, Anal. Bioanal. Chem. 381 (2005) 1452-1459.

[21] http://www.seafriends.org.nz/oceano/seawater.htm.

[22] E. Rosland, W. Lund, Direct determination of trace metals in sea-water by inductively coupled plasma mass spectrometry, J. Anal. At. Spectrom. 13 (1998) 1239-1244

[23] Y.Z. Han, Standard Reference Materials Handbook, China Metrology Publishing House, Beijing, 1998, p. 529. 